\title{
KINETICS CONSIDERATION OF ETHANOL LEAVES EXTRACT OF COSTUS LUCANUSIANUS AS GREEN CORROSION INHIBITOR FOR MILD STEEL AND ALUMINIUM IN HCL SOLUTION
}

\author{
Obot, A. S ${ }^{1} \square\left(\right.$ ID , Boekom, E. J ${ }^{1}$, Ita, B. N ${ }^{1}$, Utam, E. C ${ }^{1}$ \\ ${ }^{1}$ Department of Chemistry, University of Uyo, P.M.B. 1017, Uyo, Akwa Ibom State, Nigeria.
}

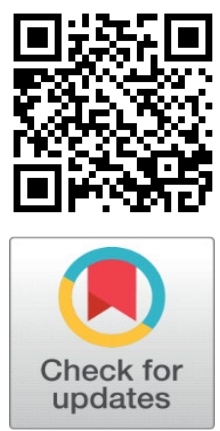

Received 6 December2021

Accepted 17 December2021

Published 31 January 2022

\section{CorrespondingAuthor}

Obot, A. S,

anneobott@gmail.com

DOI

10.29121/granthaalayah.v10.i1.2022 4461

Funding: This research received no specific grant from any funding agency in the public, commercial, or not-for-profit sectors.

Copyright: (C) 2022 The Author(s). This is an open access article distributed under the terms of the Creative Commons Attribution License, which permits unrestricted use, distribution, and reproduction in any medium, provided the original author and source are credited.

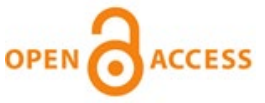

\section{ABSTRACT}

The chemical composition of ethanol leaves extract of Costus lucanusianus (ELECL) was evaluated by Gas Chromatography-Mass Spectroscopy (GC-MS) for corrosion inhibition of mild steel and aluminium in $1 \mathrm{M} \mathrm{HCl}$ using weight loss technique. A total of 18 compounds were identified. 11-Octadecenoic acid, methyl ester (30.01\%); 9Octadecenoic acid, 12-hydroxy-, methyl ester, [R-(Z)]- (25.53\%); 9,12-Octadecadienoic acid, methyl ester (13.52\%); and Hexadecanoic acid, methyl ester (13.14\%) were the major counpounds. The weight loss analysis showed ELECL as an effective corrosion inhibitor at low temperatures for mild steel and aluminium. At $1 \mathrm{~g} / \mathrm{l}$ concentration, the inhibitory action of the extracts attained an inhibition efficiency of $94 \%$ and $79 \%$ in 1 $\mathrm{g} / \mathrm{l}$ at $313 \mathrm{~K}$ and $303 \mathrm{~K}$ for mild steel and aluminium respectively. The extracts inhibitor compounds covered the metal surfaces following Freundlich adsorption isotherm. The enthalpy change showed an endothermic process while the entropy chnage showed an orderly adsorption of the inhibitor molecules on the metal surfaces.

Keywords: Corrosion, Inhibition, Gas Chromatography-Mass Spectroscopy, Adsorption Isotherm, Corrosion Kinetics

\section{INTRODUCTION}

Corrosion is an electrochemical process which generally occurs in the presence of oxygen, aqueous electrolyte solution and moisture. It could be over the entire surface of a metal or alloy, and it occurs electrochemically between two different metallic materials or two points on the surface of alloys of different chemical activity Potgieter (2010). The rate of corrosion is expressed based on the loss per unit time. The rate at which the attack takes place is of prime importance and is usually expressed in one of the two ways: Weight loss per unit area per unit time and decrease in thickness per unit time (that is, rate of penetration or the thickness of metal) Geethamani (2019).

Inhibition is a preventive measure against corrosive attack on metallic materials. One of the extensively studied topics in the field of corrosion is inhibition Geethamani (2019). Corrosion inhibitors are chemical substances added to a liquid or gas, that decrease the corrosion rate or prevent corrosion of the metal, when added in small amounts to the environment in which a metal would corrode. The effectiveness of a corrosion inhibitor depends on fluid composition, quantity of water, and flow regime. A common mechanism for inhibiting corrosion involves formation of a coating, often a passivation layer, which prevents access of the corrosive substance to the metal. However, 
corrosion inhibitors are additives to the fluids that surround the metal Guo et al. (2020).

The phenomenon of adsorption is influenced by the nature and surface charge of the metal and chemical structure of inhibitors. Inhibitors often work by adsorbing themselves on the metallic surface to protect the metallic surface by forming a film. Inhibitors are normally distributed from a solution or dispersion. Some are included in a protective coating formulation. According to Rani and Basu (2012), inhibitors decrease or prevent the reaction of the metal with the media. They reduce the corrosion rate by adsorption of ions/molecules onto metal surface, increasing or decreasing the anodic and/or cathodic reaction, decreasing the diffusion rate for reactants to the surface of the metal and decreasing the electrical resistance of the metal surface.

Literature study showed that numerous plant parts extracts including bark, leave, fruit, peel, seed, root, flower, and even entire plant extracts are widely used as corrosion inhibitors. Out of several extracts, leaves extract generally showed reasonably better protection effectiveness at relatively low concentration Alrefaee et al. (2020). Plants are natural, green, renewable, easy to access, and contain many heterocyclic organics, thereby making it one of the most suitable in replacing conventional toxic inhibitors Li et al. (2021). Consequently, plant extracts as green and effective corrosion inhibitors are wildly explored. The mechanism of action for green inhibitors depends on the structure of the active ingredient. The adsorption of natural corrosion inhibitors on metal surfaces is influenced by a number of factors including nature of metal, testing media, chemical structure of inhibitor, nature of the inhibitor constituents, presence of additives, solution temperature, and solution concentration Verma and Quraishi (2016).

Costus lucanusianus (Figure 1) commonly known as monkey sugarcane is a vigorous grower and a medicinal plant used to treat various ailments in tropical Africa. C. lucanusianus is very similar to Costus afer (bush cane), differing in their hairy leaf sheath. Besides being used as a medicinal plant, it is often used as ornamental for its flowers with showy labellum which last singularly one day only but are continuously produced. In southern Nigeria, Costus afer and C. Iucanusianus produce hybrids. The methanol and n-hexane extracts have been reported to act as inhibitors. However, they contained different constituents Obot et al. (2021a), Obot et al. (2021b). Therefore, this study seeks to investigate the constituents of the ethanol extract and its inhibitory potential on mild steel and aluminium in $1 \mathrm{M} \mathrm{HCl}$.

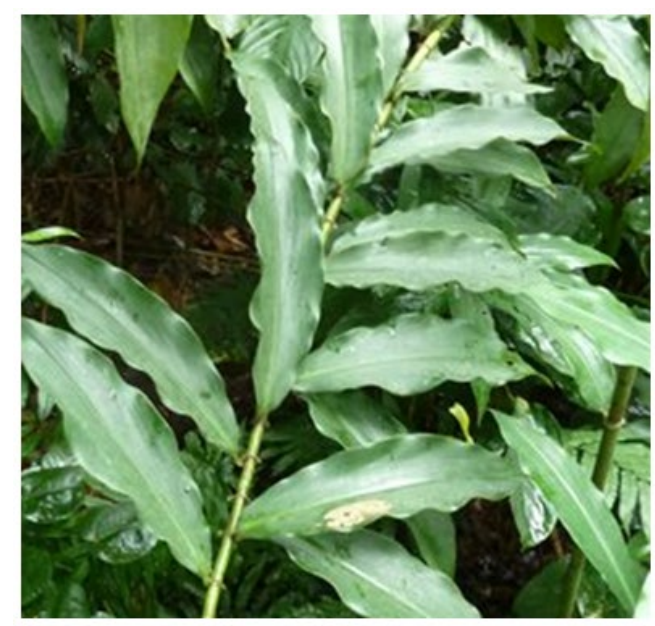

Figure 1 Costus lucanusianus plant 


\section{MATERIALS AND METHODS \\ 2.1. SAMPLE COLLECTION PREPARATION}

The fresh leave samples of $C$. lucanusianus leave were rinsed and dried at room temperature, crushed and ground into fine powder. Extraction with ethanol was performed. 70 g leaves were soaked in $900 \mathrm{ml}$ ethanol for 72 hours and filtered. The filtrate was allowed to evaporate completely $40^{\circ} \mathrm{C}$ using Stuart Rotatory Evaporator (Re 300) to remove the ethanol solvent. Different weights of the extract were measured and used to prepare five different concentrations $(1 \mathrm{~g} / \mathrm{l}, 0.7 \mathrm{~g} / \mathrm{l}, 0.5 \mathrm{~g} / \mathrm{l}$, $0.2 \mathrm{~g} / \mathrm{l} 0.1 \mathrm{~g} / \mathrm{l}$ ) in $1 \mathrm{M} \mathrm{HCl}$.

\subsection{COUPONS}

The experiment was conducted on mild steel with the following composition carbon $-0.17 \%$, silicon $-0.26 \%$, manganese $-0.46 \%$, phosphorus $-0.0047 \%$, sulphur $-0.017 \%$, iron -98.9\%) and pure aluminium metal of the type of AA 1060. The coupons with dimensions $4 \times 4 \mathrm{~cm}$ was used for weight loss measurements. For the insertion of hook, a hole was drilled at the top centre of the coupons. The coupons were brushed with series of emery paper of variable grades starting with the course (100) to the finest (1200) grade to obtain a smooth surface free of grooves. Each coupon was degreased by washing with ethanol, dried with acetone and stored in a desiccator.

\subsection{GAS CHROMATOGRAPHY-MASS SPECTROSCOPY (GC-MS)}

The chromatographic analysis of the ethanol stem extract of $C$. lucanusianus was carried out using Agilent technologies 7890A GC and 5977B MSD. The system was equipped with $\mathrm{Hp} 5$-MS capillary standard non-polar column $(30 \mathrm{~m} \times 0.25 \mathrm{~mm}$ $\times 0.5 \mu \mathrm{m}$ film thickness). The temperature was set from $25^{\circ} \mathrm{C}$ to $40^{\circ} \mathrm{C}$ at $5^{\circ} \mathrm{C} / \mathrm{min}$ and injection volume was $1 \mu \mathrm{l}$. Helium gas was used as a carrier gas with a constant flow rate of $1.0 \mathrm{ml} / \mathrm{min}$. Samples dissolved in methanol were fully scanned at the range of $40-650 \mathrm{~m} / \mathrm{z}$ and the results were compared by using NIST mass spectral library search programme.

\subsection{WEIGHT LOSS EXPERIMENT}

Weight loss experiment was performed to determine the concentration influence of ethanol extracts of $C$. lucanusianus on mild steel and aluminium coupons. the coupons were immersed in a test solution containing different concentrations of the extract. The system was maintained at $303 \mathrm{~K}, 313 \mathrm{~K}, 323 \mathrm{~K}$ and $333 \mathrm{~K}$ using a thermostat water bath. After immersion, the coupons were washed with distilled water, scrubbed with bristled brush to remove the corrosion product, cleansed with ethanol, dried in acetone and reweighed at 2-hours intervals progressively for 10-hours. Using Equation 1, the weight loss was taken to be the difference between the initial weight and the weight of the coupons at 2 hours intervals

$$
\Delta \mathrm{W}=\left(\mathrm{W}_{0}-\mathrm{W}_{1}\right) \mathrm{g}
$$

Equation 1 
The corrosion rate (CR), surface coverage $(\theta)$ and inhibition efficiency (\%IE) were computed using the Equation 2, Equation 3, Equation 4 respectively

$$
\mathrm{CR}=\frac{\Delta \mathrm{W}}{\mathrm{St}}\left(\mathrm{g} / \mathrm{cm}^{2} \mathrm{hr}\right)
$$

Where $\Delta \mathrm{W}$ is the weight loss, $\mathrm{S}$ is the total surface area of the coupons and $\mathrm{t}$ is the corrosion time (10hrs).

$$
\begin{aligned}
& \theta=\frac{\mathrm{CR}_{0}-\mathrm{CR}_{1}}{\mathrm{CR}_{0}} \\
& \% \mathrm{IE}=\frac{\mathrm{CR}_{0}-\mathrm{CR}_{1}}{\mathrm{CR}_{0}} \mathrm{X} 100
\end{aligned}
$$

Equation 4

Where $\mathrm{CR}_{0}$ is the corrosion rate in the absence of inhibitor, while $\mathrm{CR}_{1}$ is the corrosion rate in the presence of inhibitor.

\section{RESULTS AND DISCUSSION}

\subsection{GAS CHROMATOGRAPHY-MASS SPECTROSCOPY (GC-MS)}

The GC-MS analysis of ELECL showed the presence of 18 compounds compounds. Table 1 presents the identified compounds of ELECL with their retention time, pecentage area, compound name, CAS number and structures.

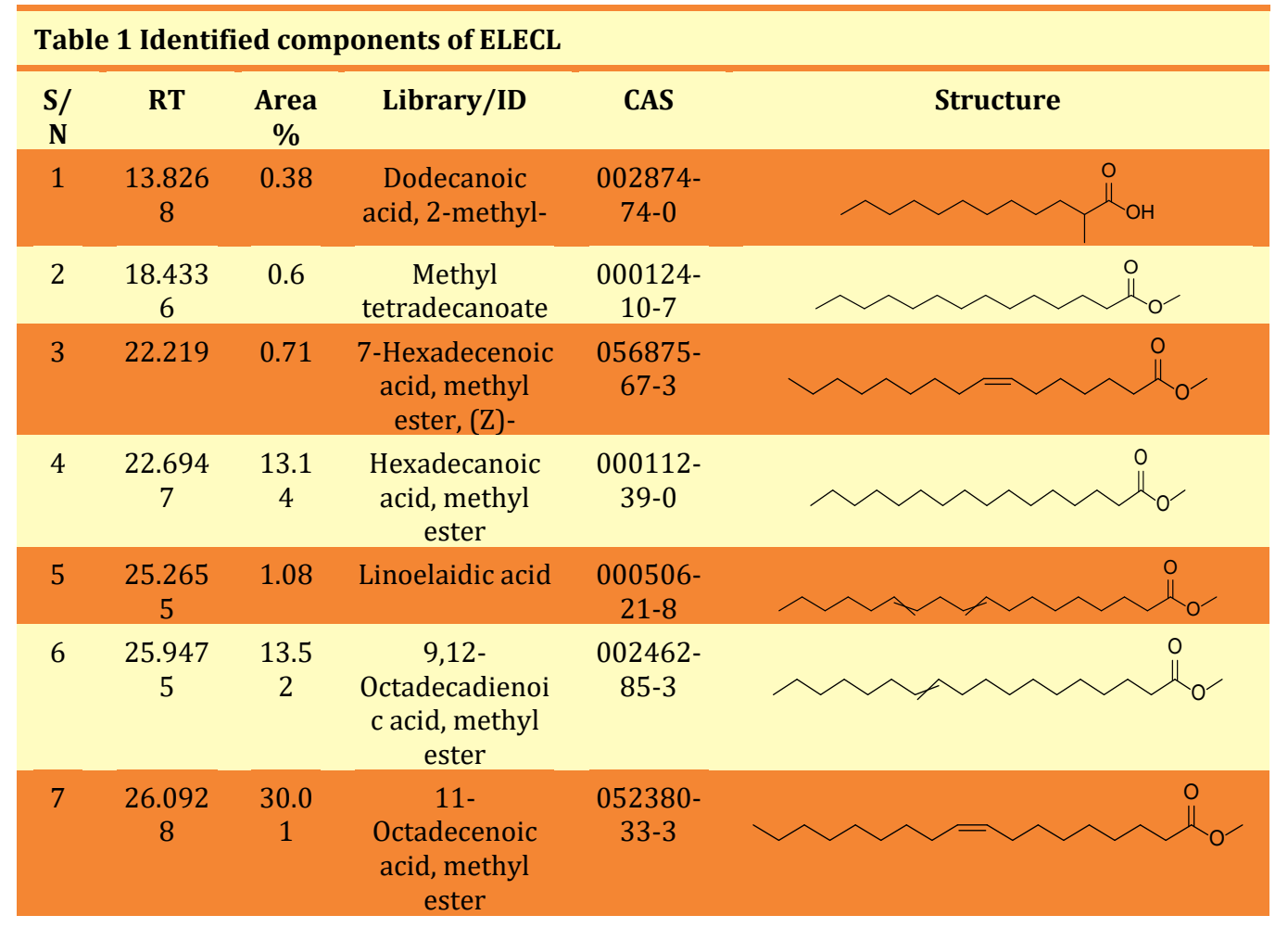




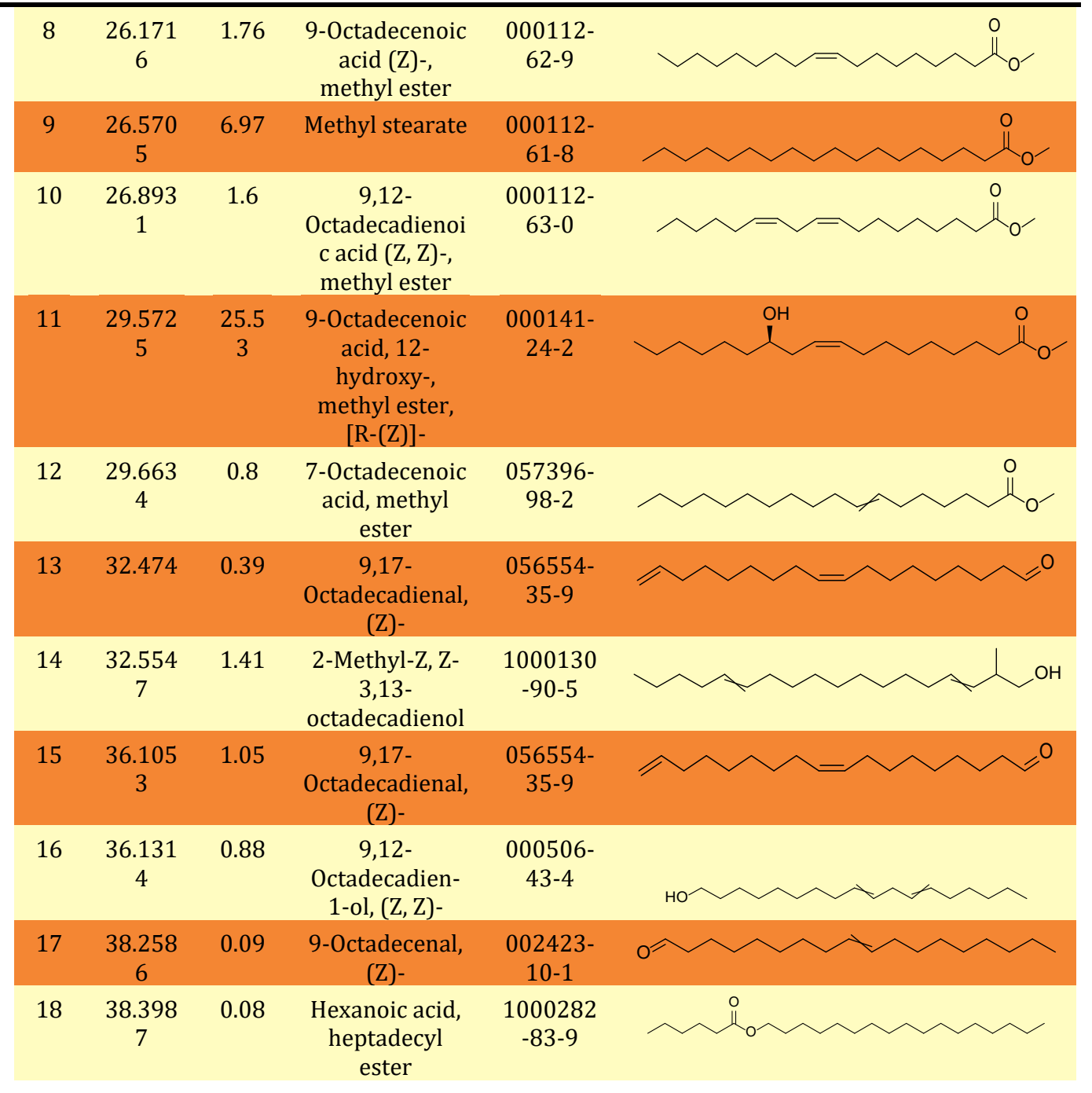

The identified compounds contain oxygen as a heteroatom in their structures. This property suggests the use of the leave extract of $C$. lucanusianus as corrosion inhibitor. 11-Octadecenoic acid, methyl ester (30.01\%); 9-Octadecenoic acid, 12hydroxy-, methyl ester, [R-(Z)]- (25.53\%); 9,12-Octadecadienoic acid, methyl ester (13.52\%); and Hexadecanoic acid, methyl ester (13.14\%) was identified as the predominant compounds.

\section{WEIGHT LOSS ANALYSIS}

The weight loss experiment was carried out to determine ELECL shielding proficiency at consecutively increasing concentrations. The calculated values of corrosion rate (CR), degree of surface coverage $(\theta)$ and inhibition efficiency (\% IE) of mild steel and aluminium at $303 \mathrm{~K}$ to $333 \mathrm{~K}$ in the presence and absence of ELECL are tabulated in Table 2.

The data shows that the inhibition process was a concentration dependent one. While the concentration of the extracts increased, the corrosion rate decreased. Therefore, the corrosion inhibition activity of ELECL advanced with concentration; and showed maximum inhibitive effect of $94 \%$ and $79 \%$ for mild steel and aluminium, respectively at low temperature. The results also suggest larger corrosion protection of the steel surface that is confirmed by the rising value of 
surface coverage $(\theta)$ Jesudoss et al. (2020). The ability of the extract's natural chemical constituents to adsorb onto the metal surface is mainly the reason for its corrosion resistance ability Zaher et al. (2021). The proportion of surface covered with adsorbed extract molecules determines the amount of corrosion protection. Therefore, as the adsorbed molecules of extract grow on the metal surface, its concentration increases, thereby making the $\theta$ value a critical variable since it reflects the percentage of metal substrate surface covered by extract molecules Zaher et al. (2021)

\begin{tabular}{|c|c|c|c|c|c|c|c|c|c|c|c|c|}
\hline & $303 \mathrm{~K}$ & & & $313 \mathrm{~K}$ & & & $323 \mathrm{~K}$ & & & $333 \mathrm{~K}$ & & \\
\hline $\begin{array}{l}\text { Conc. } \\
\text { (g/L) }\end{array}$ & $\begin{array}{c}\text { CR } \\
\mathrm{g} / \mathrm{cm}^{2} \mathrm{~h} \times \\
10^{-3}\end{array}$ & $\boldsymbol{\theta}$ & $\%$ IE & $\begin{array}{c}\text { CR } \\
\mathrm{g} / \mathrm{cm}^{2} \mathrm{~h} \times \\
10^{-3}\end{array}$ & $\boldsymbol{\theta}$ & $\%$ IE & $\begin{array}{c}\text { CR } \\
\mathrm{g} / \mathrm{cm}^{2} \mathrm{~h} \times \\
10^{-3}\end{array}$ & $\boldsymbol{\theta}$ & $\%$ IE & $\begin{array}{c}\text { CR } \\
\mathrm{g} / \mathrm{cm}^{2} \mathrm{~h} \times \\
10^{-3}\end{array}$ & $\boldsymbol{\theta}$ & $\%$ IE \\
\hline \multicolumn{13}{|c|}{ MILD STEEL } \\
\hline Blank & 1.93 & - & - & 10.93 & - & - & 13.96 & - & - & 17.05 & - & - \\
\hline 0.1 & 1.87 & 0.03 & 3 & 6.61 & 0.39 & 39 & 11.88 & 0.15 & 15 & 16.34 & 0.04 & 4 \\
\hline 0.2 & 1.81 & 0.06 & 6 & 6.33 & 0.42 & 42 & 9.9 & 0.29 & 29 & 14.72 & 0.14 & 14 \\
\hline 0.5 & 1.35 & 0.3 & 30 & 5 & 0.54 & 54 & 5.69 & 0.59 & 59 & 13.59 & 0.2 & 20 \\
\hline 0.7 & 1.17 & 0.39 & 39 & 1.71 & 0.84 & 84 & 5.3 & 0.62 & 62 & 9.39 & 0.45 & 45 \\
\hline 1 & 0.62 & 0.68 & 68 & 0.61 & 0.94 & 94 & 2.15 & 0.85 & 85 & 5.4 & 0.68 & 68 \\
\hline \multicolumn{13}{|c|}{ ALUMINIUM } \\
\hline Blank & 5.35 & - & - & 8.82 & - & - & 11.42 & - & - & 12.28 & - & - \\
\hline 0.1 & 3.27 & 0.39 & 39 & 5.7 & 0.35 & 35 & 9.49 & 0.17 & 17 & 9.52 & 0.23 & 23 \\
\hline 0.2 & 3.17 & 0.41 & 41 & 5.42 & 0.39 & 39 & 8.66 & 0.24 & 24 & 9.32 & 0.24 & 24 \\
\hline 0.5 & 2.24 & 0.58 & 58 & 5.22 & 0.41 & 41 & 8.1 & 0.29 & 29 & 8.51 & 0.31 & 31 \\
\hline 0.7 & 2.03 & 0.62 & 62 & 4.11 & 0.53 & 53 & 7.84 & 0.31 & 31 & 8.53 & 0.31 & 31 \\
\hline 1 & 1.13 & 0.79 & 79 & 3.85 & 0.56 & 56 & 5.46 & 0.52 & 52 & 3.98 & 0.68 & 68 \\
\hline
\end{tabular}

\subsection{EFFECTT OF TEMPERATURE}

The weight loss analysis of mild steel and aluminium was studied in the temperature range $303 \mathrm{~K}-333 \mathrm{~K}$ in inhibited and uninhibited solutions. Figure 2 shows the variation of inhibition efficiencies of ELECL with concentration and temperature for mild steel and aluminium. The inhibition efficiency (\%IE) for mild steel and aluminum increased with increasing concentrations of the extract. The maximum inhibition efficiencies (94\% and $79 \%$ ) at $1 \mathrm{~g} / \mathrm{l}$ were attained at $313 \mathrm{~K}$ and $303 \mathrm{~K}$ for mild steel and aluminium, respectively. This indicates that the extract molecules are adsorbed on metal-solution interface forming a protected layer on the metal surface that hindered its corrosion Fouda et al. (2021). However, decrease in the extract efficiency with increasing temperature indicates desorption of extract molecules on the metal surfaces. This behaviour is consistent with physical adsorption mechanism Ituen et al. (2021) 
MILD STEEL

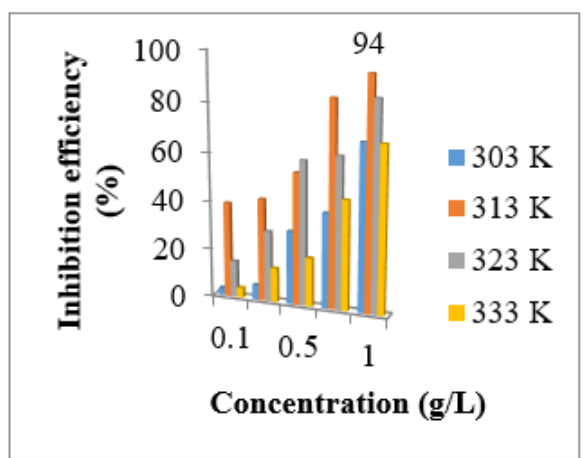

ALUMINIUM

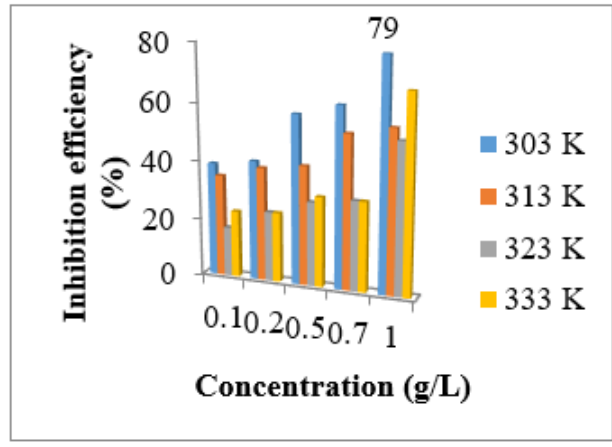

Figure 2 Variation of inhibition efficiencies of ELECL with concentration and temperature for mild steel and aluminium

\subsection{MECHANISM OF ADSORPTION}

The inhibitor molecules adsorption onto metal surface is divided into chemical and physical adsorption Tan et al. (2021). This process gives the interation details between the inhibitors and metal surfaces. However, while physical adsorption involves interaction between the charged corrosion inhibitor and the charged metal, chemical adsorption involves the formation of coordination bonds with the metal unoccupied orbitals with lone pairs of heteroatoms in the inhibitor molecule. Variety of adsorption isotherms including Langmuir, Temkin, Fruendlich and ElAwady isotherms were used to fit the weight loss data. These isotherms were expressed using the following equations respectively Ituen and Udo (2012):

$$
\begin{aligned}
& \frac{C}{\theta}=\frac{1}{K_{a d s}}+C \\
& \theta=-\frac{1}{2 a} \log C-\frac{1}{2 a} \log K \\
& \log \theta=\log K+n \log C \\
& \log \frac{\theta}{1-\theta}=\log K^{*}+y \log C
\end{aligned}
$$

Equation 5

Equation 6

Equation 7

Where $\mathrm{C}$ is the concentration, $\mathrm{K}_{\mathrm{ads}}$ is the adsorption equilibrium constant, $\mathrm{a}$ is the molecular interaction parameter used to predict the nature of interactions in the adsorbed layer and $\theta$ is the surface coverage.

The freundlich adsorption isotherm (Figure 3) provided the best fit and described the adsorption behaviour of the extracts of $C$. lucanusianus presented in Table 3. Investigation of the adsorption characteristics as provided in Table 3, showed that the inhibitor exhibited more of a monolayer chemical adoption Ugi 
(2020) as data fit accurately to the isotherm as seen in the correlation coefficient obtained from the plots (Figure 3$)$ which are in the range $\left(0.8767 \leq \mathrm{R}^{2} \leq 0.9904\right)$ for mild steel and $\left(0.6486 \leq \mathrm{R}^{2} \leq 0.9355\right)$ for aluminium.

The value of $\Delta G_{a d s}^{0}$ was obtained by following: Zhang et al. (2018), Li et al. (2018), Fatima et al. (2019)

$$
K_{a d s}=\frac{1}{55.5} \exp \frac{-\Delta G_{a d s}^{0}}{R T}
$$

Equation 9

the negative values of $\Delta G_{a d s}^{0}$ indicate a spontaneous adsorption of the inhibitor molecules on the metal surfaces. The $\Delta G_{a d s}^{0}$ value determines the type of adsorption. When the value is greater than $-20 \mathrm{~kJ} / \mathrm{mol}$, it reveals that the charged corrosion inhibitor and the charged metal have physical adsorption through electrostatic attraction Sadeghi et al. (2019). When the value is less than $-40 \mathrm{~kJ} / \mathrm{mol}$, it reveals that the interaction between the inhibitor molecules and the metal surface is chemisorption Biswas et al. (2018). When the value is between $-20 \mathrm{~kJ} / \mathrm{mol}$ and -40 $\mathrm{kJ} / \mathrm{mol}$, it reveals that it is a mixed physical and chemical adsdorption process Zhang et al. (2018). From Table 3, it can be seen that the $\Delta G_{a d s}^{0}$ values are greater than -20 $\mathrm{kJ} / \mathrm{mol}$ at varied temperatures, therefore the mechanism of adsorption followed by ELECL is believed to be physical adsorption.

Table 3 Adsorption parameters from Freundlich isotherm for mild steel and aluminium in different concentrations of ELECL at $303 \mathrm{~K}$ to $333 \mathrm{~K}$

\begin{tabular}{|c|c|c|c|c|}
\hline \multirow[t]{2}{*}{ Inhibitor } & \multirow[t]{2}{*}{ Temp (K) } & \multicolumn{3}{|c|}{ Adsorption parameters } \\
\hline & & Kads (mol/l) & $\Delta \mathrm{G}(\mathrm{kJ} / \mathrm{mol})$ & $\mathbf{R}^{2}$ \\
\hline \multirow[t]{4}{*}{ Mild steel } & $303 \mathrm{~K}$ & 0.8458 & -3.7163 & 0.9904 \\
\hline & $313 \mathrm{~K}$ & 0.9409 & -4.2708 & 0.8767 \\
\hline & $323 \mathrm{~K}$ & 0.9444 & -4.4237 & 0.9836 \\
\hline & $333 \mathrm{~K}$ & 0.8156 & -3.9387 & 0.9456 \\
\hline \multirow[t]{4}{*}{ Aluminium } & $303 \mathrm{~K}$ & 0.8711 & -3.8277 & 0.9355 \\
\hline & $313 \mathrm{~K}$ & 0.7632 & -3.4642 & 0.8578 \\
\hline & $323 \mathrm{~K}$ & 0.6904 & -3.2337 & 0.8695 \\
\hline & $333 \mathrm{~K}$ & 0.72 & -3.4772 & 0.6486 \\
\hline
\end{tabular}

MILD STEEL

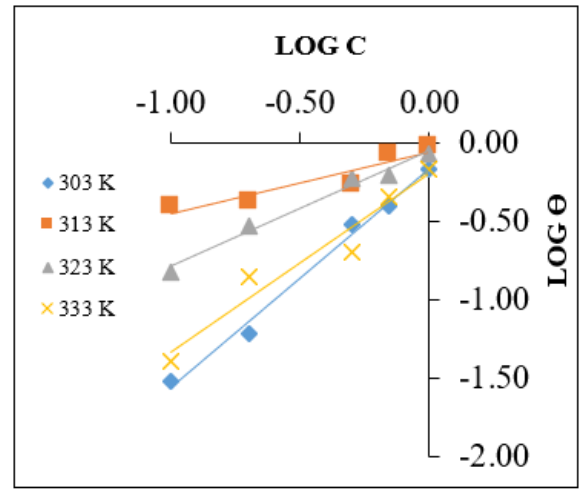

ALUMINIUM

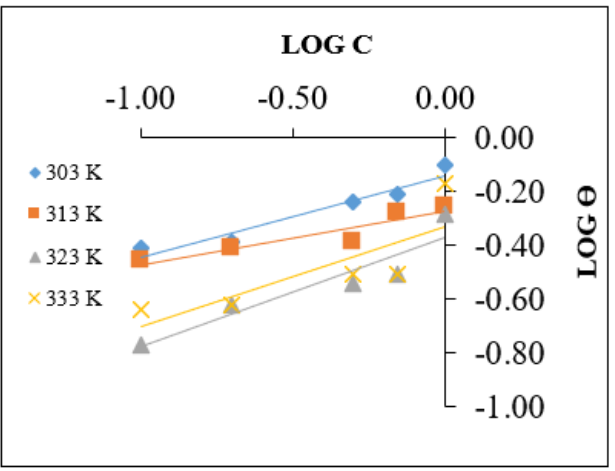

Figure 3 Freundlich adsorption isotherm plot (C/ $\Theta$ versus $C$ ) for mild steel and aluminium 


\subsection{CORROSION KINETIC ANALYSIS}

The Arrhenius and transition state equations was used to consider the kinetic parameters of ELECL adsorption on mild steel and aluminium surfaces. The activation energy Ea, enthalpy and entropy of activation were calculated using the Arrhenius and transition state equations, respectively as shown:

$$
\begin{aligned}
& \log C R=\log A-\frac{E_{a}}{2.303 R T} \\
& \log \frac{C R}{T}=\log \left(\frac{R}{N h}\right)+\left(\frac{\Delta S}{2.303 R}\right)-\left(\frac{\Delta H}{2.303 R T}\right)
\end{aligned}
$$

Equation 10

Equation 11

Where CR denotes the corrosion rate of mild steel and aluminium determined from the weight loss experiment, A denotes the pre-exponential constant, $E_{a}$ denotes the apparent activation energy, $\mathrm{R}$ denotes the universal gas constant, $\mathrm{T}$ denotes the temperature, $\mathrm{N}$ denotes the Avogadro's number, h drenotes Planck's constant, $\Delta \mathrm{H}$ denotes enthalpy change, and $\Delta \mathrm{S}$ denotes entropy change.

The activation energies were obtained from the slope of the linear plot of log CR against $10^{3} / \mathrm{T}$ for mild steel and aluminium in $1 \mathrm{M} \mathrm{HCl}$ in the absence and presence of different concentration of ELECL and the data presented in Table 4 show an increasing trend. An increase in the $E_{a}$ value indicated that inhibitor molecules physically adsorped on the metal surfaces. The increase in $E_{a}$ value with the addition of the inhibitor that suggests electrostatic metal-inhibitor interactions about et al. (2021) and suggests the increase of the energy barrier for the corrosion reaction, resulting in reduced rate of corrosion process Verma and Quraishi (2016).

MILD STEEL

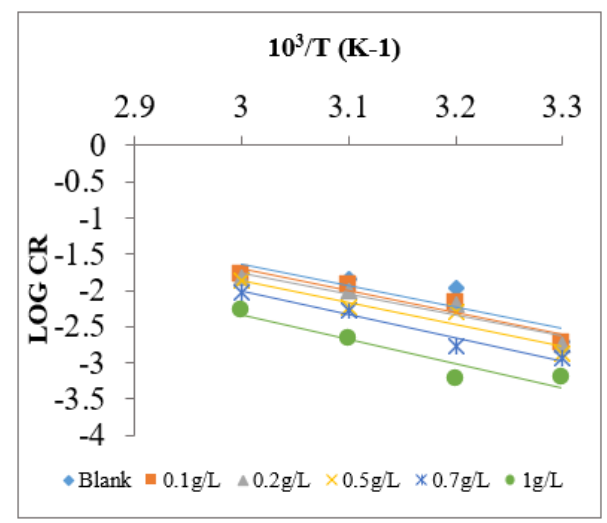

ALUMINIUM

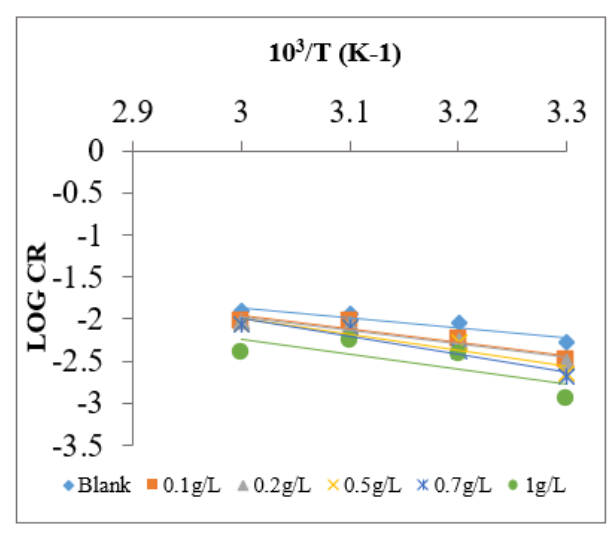

Figure 4 Arrhenius plot for mild steel and aluminium in different concentrations of ELECL

Table 4 Activation parameters from Transition State equation for mild steel in different

\begin{tabular}{|c|c|c|c|c|}
\hline Coupons & Conc. (g/L) & Kinetic parameters & & \\
\hline & & $\mathrm{E}_{\mathrm{a}}(\mathrm{J} / \mathrm{mol})$ & $\Delta \mathrm{H}(\mathrm{J} / \mathrm{mol}$ & $\Delta S(\mathrm{~J} / \mathrm{mol} . \mathrm{K})$ \\
\hline \multirow[t]{2}{*}{ Mild steel } & Blank & 24.49 & 53.7772 & -115.8147 \\
\hline & 0.1 & 25.62 & 56.3949 & -109.106 \\
\hline
\end{tabular}
concentrations of ELECL at $303 \mathrm{~K}$ to $333 \mathrm{~K}$ 
Obot, A. S, Boekom, E. J, Ita, B. N, and Utam, E. C

\begin{tabular}{ccccc} 
& 0.2 & 24.33 & 53.4151 & -119.2444 \\
& 0.5 & 25.52 & 56.1602 & -113.023 \\
Aluminium & 0.7 & 26.62 & 58.6897 & -108.4846 \\
& 1 & 28.07 & 62.0341 & -104.4608 \\
& Blank & 9.93 & 20.2558 & -220.8304 \\
& 0.1 & 13.43 & 28.305 & -198.3267 \\
& 0.2 & 13.38 & 28.2034 & -199.0475 \\
& 0.5 & 16.02 & 34.2865 & -181.0089 \\
& 0.7 & 17.87 & 38.5365 & -168.3864 \\
\hline 1 & 14.86 & 31.6131 & -193.8787
\end{tabular}

The data in Table 4 obtained from the transition state plot of $\log \mathrm{CR} / \mathrm{T}$ versus $10^{3} / \mathrm{T}$ (Figure 5) for mild steel and aluminium in $1 \mathrm{M} \mathrm{HCl}$ in the absence and presence of different concentration of ELECL show positive values of $\Delta H$ indicating an endothermic reaction. Thus, implying that the inhibitors have the potential of influencing the incoming energy in the system resulting in higher potential energy and lower kinetic energy, hence breaking up the intermolecular force between the molecules, leading to a slower corrosion reaction rate Srinivasulu and Kasthuri (2017), Gadow and Motawea (2017). The negative values of $\Delta$ S indicate a decrease in the disorderliness of the system compared with the blank Azzaoui et al. (2017) and therefore an increased orderliness in the system as a result of an orderly adsorption of the inhibitor molecules freely moving in the bulk solution onto the mild steel and aluminium metal surfaces which often indicates an associative mechanism in which both the molecules of the extracts and ions of the metals form a single activated complex, hence creating a better inhibition Cookey et al. (2018)

MILD STEEL

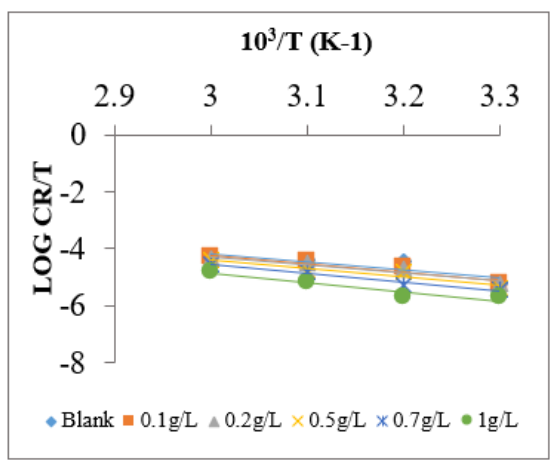

ALUMINIUM

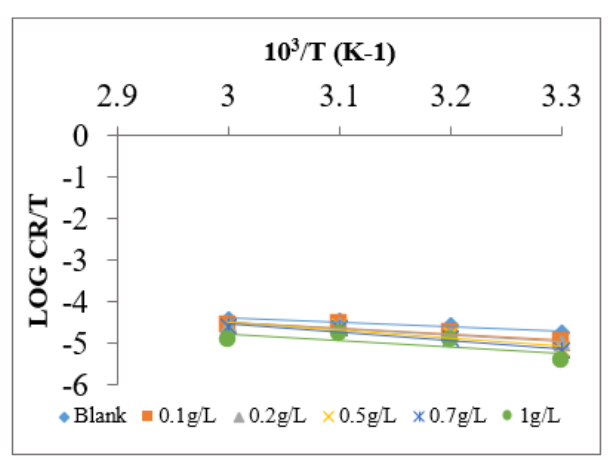

Figure 5 Transition state plot for mild steel and aluminium in different concentrations of ELECL

\section{CONCLUSION}

The Ethanol leave extract of Costus lucanusianus (ELECL) was characterized by GC-MS analysis. 11-Octadecenoic acid, methyl ester (30.01\%); 9-Octadecenoic acid, 12-hydroxy-, methyl ester, [R-(Z)]- (25.53\%); 9,12-Octadecadienoic acid, methyl ester (13.52\%); and Hexadecanoic acid, methyl ester (13.14\%) was identified as the predominant compounds, largely responsible for the inhibition. The inhibition study was carried out using weight loss method. The inhibition efficiency reached values of $94 \%$ and $79 \%$ for mild steel and aluminium respectively at $1 \mathrm{~g} / \mathrm{l}$ concenentration. The Freundlich adsorption showed that the adsorption process of 
ELECL was physisorption, the enthalpy showed an endothermic process while the entropy values showed an orderly adsorption of the inhibitor molecules onto the metal surfaces.

\section{REFERENCES}

Abbout, S., Chebabe, D., Zouarhi, M., Rehioui, M., Lakbaibi, Z. and Hajjaji, N. (2021). Ceratonia Siliqua L seeds extract as eco-friendly corrosion inhibitor for carbon steel en $1 \mathrm{M} \mathrm{HCl}$ : Characterization, electrochemical, surface analysis, and theoretical studies. Journal of Molecular Structure, 1240 : 130611. Retrieved from https://doi.org/10.1016/j.molstruc.2021.130611

Alrefaee, S. H., Rhee, K. Y., Verma, C., Quraishi, M. A. and Ebenso, E. E. (2020). Challenges and advantages of using plant extract as inhibitors in modern corrosion inhibition systems : Recent advancements. Journal of Molecular Liquids, $\quad 114666 . \quad$ Retrieved from https://doi.org/10.1016/j.molliq.2020.114666

Azzaoui, K., Mejdoubi, E., Jodeh, S., Lamhamdi, A., Rodriguez-Castello' n, E., Algarra, M., Zarrouk, A., Errich, A., Salghi, R. and Lgaz, H. (2017). Eco friendly green inhibitor Gum Arabic (GA) for the corrosion control of mild steel in hydrochloric acid medium. Corrosion Science, $129: 70-81$. Retrieved from https://doi.org/10.1016/j.corsci.2017.09.027

Biswas, A., Mourya, P., Mondal, D., Pal, S. and Udayabhanu, G. (2018). Grafting effect of gum acacia on mild steel corrosion in acidic medium : gravimetric and electrochemical study, Journal of Molecular Liquid, 251 : 470-479. Retrieved from https://doi.org/10.1016/j.molliq.2017.12.087

Cookey, G. A., Tambari, B. L. and Iboroma, D. S. (2018). Evaluation of corrosion inhibition potentials of green tip forest lily (Clivia no-bilis) leaves extract on mild steel in acid media. Journal of applied Sciences and Environmental Management, 22(1) :90-94. Retrieved from https://doi.org/10.4314/jasem.v22i1.16

Fatima, S., Sharma, R., Asghar, F., Kamal, A., Badshah, A. and Kraatz, H.-B. (2019). Study of new amphiphiles based on ferrocene containing thioureas as efficient corrosion inhibitors : gravimetric, electrochemical, SEM and DFT studies. Journal of Industrial and Engineering Chemistry, 76 : 374-387. Retrieved from https://doi.org/10.1016/j.jiec.2019.04.003

Fouda, A. S., Mohamed O. A. and Elabbay, H. M. (2021). Ferula hermonis Plant Extract as Safe Corrosion Inhibitor for Zinc in Hydrochloric Acid Solution. Journal of Bio- and Tribo-Corrosion, 7 :135. Retrieved from https://doi.org/10.1007/s40735-021-00570-z

Gadow, H. S. and Motawea, M. M. (2017). Investigation of the corrosion inhibition of carbon steel in hydrochloric acid solution by using ginger roots extract. Royal Society of Chemistry Advances, 7(40) :24576-24588. Retrieved from https://doi.org/10.1039/C6RA28636D

Geetha, K. and Udhayakumar, R. (2021). A green tactic for inhibition of corrosion on mild steel in bore well water by aqueous extract of Bauhinia Blakeana leaves. Indian Journal of Chemical Technology, 28 : 36-46. Retrieved from http://nopr.niscair.res.in/handle/123456789/56533

Geethamani, P. (2019). Corrosion Inhibitors. In : A. Singh, (Ed.). Corrosion Inhibitors. Intechopen Books, London, United Kingdom, 24p. 
Guo, L., Tan, B., Li, W., Li, Q., Zheng, X. and Bassey, I. (2020). Banana leaves water extracts as inhibitor for X70 steel corrosion in $\mathrm{HCl}$ medium. Journal of Molecular Liquids, 327 : 114828-114839. Retrieved from https://doi.org/10.1016/j.molliq.2020.114828

Ituen, E. I. and Udo, U. E. (2012). Phytochemical profile, adsorption and inhibitive behaviour of costus afer extracts on aluminium corrosion in hydrochloric acid. Pelagia Research Library, 3(6) : 1394-1405. Retrieved from http://www.pelagiaresearchlibrary.com/der-chemica-sinica/vol3iss6/DCS-2012-3-6-1394-1405.pdf

Ituen, E., Dim, C. and BoEKOM, E. (2021). Orange Peel Extract Mediated Silver Nanofluid a Corrosion Inhibitor for X80 Steel in Simulated Oilfield Scale Dissolver. Journal of Metallic Material Research, 04(01), 41-45. Retrieved from https://doi.org/10.30564/jmmr.v4i1.3621

Jesudoss, N. R., Meby, H. R., Tezeghdenti, S., Mukesh, A. M., Olfa, K. and Nikolova, M. P. (2020). Aerva lanata flowers extract as green corrosion inhibitor of low carbon steel in $\mathrm{HCl}$ solution : an in vitro study. Chemical Papers, 0123456789. Retrieved from https://doi.org/10.1007/s11696-020-013615

Li, H., Qiang, Y., Zhao, W. and Zhang, S. (2021). A green Brassica oleracea L extract as a novel corrosion inhibitor for Q235 steel in two typical acid media. Colloids and Surfaces A : Physicochemical and Engineering Aspects, 616 : 126077. Retrieved from https://doi.org/10.1016/j.colsurfa.2020.126077

Li, X., Deng, S., Lin, T., Xie, X. and Du, G. (2018). Cassava starch-sodium allylsulfonateacrylamide graft copolymer as an effective inhibitor of aluminum corrosion in $\mathrm{HCl}$ solution. Journal of Taiwan Institute of Chemical Engineers, $86: 252$ 269. Retrieved from https://doi.org/10.1016/j.jtice.2018.03.002

Obot, A. S., BoEKOM, E. J., Obot, I. B., Ita, B. N. and Azubuike, A. C. (2021a). Chemical evaluation and quantum analysis of methanol extracts of Costus lucanusianus as corrosion inhibitors for mild steel and aluminium en $1 \mathrm{M}$ $\mathrm{HCl}$ solution. Elixir Corrosion and Dye, 159 : 55648-55660.

Obot, A. S., BoEKOM, E. J., Ugi, B. U., Essien, K. E. and Jonah, N. B. (2021b). Thermodynamic investigation and quantum chemical evaluation of $\mathrm{n}$ hexane extracts of Costus lucanusianus as corrosion inhibitors for mild steel and aluminum en $1 \mathrm{M} \mathrm{HCl}$ solution. Journal of Applied Physical Science International, 13(3) : 6-27.

Potgieter, J. H. (2010). Corrosion of passive alloys : The effect of noble metal additions. Shreir's Corrosion, 3 : 2224-2249. Retrieved from https://doi.org/10.1016/B978-044452787-5.00188-8

Rani, B. E. A. and Basu, B. B. J. (2012). Green inhibitors for corrosion protection of metals and alloys : An overview. International Journal of Corrosion, 2012 : 1687-9325. Retrieved from https://doi.org/10.1155/2012/380217

Sadeghi E. R., Amirnasr, M., Meghdadi, S., Talebian, M., Farrokhpour, H. and Raeissi, K. (2019). Carboxamide derivatives as new corrosion inhibitors for mild steel protection in hydrochloric acid solution, Corrosion Science, 151 : 190197. Retrieved from https://doi.org/10.1016/j.corsci.2019.02.019

Srinivasulu, A. and Kasthuri, P. K. (2017). Study of inhibition and adsorption properties of mild steel corrosion by expired pharmaceutical gentamicin drug in hydrochloric acid media. Oriental Journal of Chemistry, 33(5) : 26162624. Retrieved from https://doi.org/10.13005/ojc/330559 
Tan, B., Xiang, B., Zhang, S., Qiang, Y., Xu, L., Chen, S. and He, J. (2021). Papaya leaves extract as a novel eco-friendly corrosion inhibitor for $\mathrm{Cu}$ in $\mathrm{H} 2 \mathrm{SO} 4$ medium. Journal of Colloid and Interface Science, 582 : 918-931. Retrieved from https://doi.org/10.1016/j.jcis.2020.08.093

Ugi, B. U. (2020). Effects of Nitrogen Atoms in Vindoline Alkaloids as Fe2+ Ions Inhibitor in Corrosion of Gray Iron in Dilute $\mathrm{HCl}$ Environment : Potentiodynamic Polarization, Gravimetric Analysis and SEM. Journal of Materials and Environmental Science, 11(8) :1274-1285.

Verma, C. and Quraishi, M. A. (2016). Adsorption behavior of 8,9-bis (4 (dimethyl amino) phenyl) benzo [4,5] imidazo[1,2-a] pyridine-6,7-dicarbonitrile on mild steel surface in $1 \mathrm{M} \mathrm{HCl}$. Journal of the Association of Arab Universities for Basic and Applied Sciences, 22(1) : 55-61. Retrieved from https://doi.org/10.1016/j.jaubas.2016.01.003

Zaher, A., Aslam, R., Lee, H., Khafouri, A., Boufellous, M., Alrashdi, A. A., El-Aoufir, Y., Lgaz, H. and Ouhssine, M. (2021). A combined computational and electrochemical exploration of the Ammi visnaga L. extract as à green corrosion inhibitor for carbon steel in $\mathrm{HCl}$ solution. Arabian Journal of Chemistry, 15(2), $103573 . \quad$ Retrieved from https://doi.org/10.1016/j.arabjc.2021.103573

Zhang, K., Yang, W., Xu, B., Chen, Y., Yin, X., Liu, Y. and Zuo, H. (2018). Inhibitory effect of konjac glucomanan on pitting corrosion of AA5052 aluminium alloy in $\mathrm{NaCl}$ solution. Journal of Colloid Interface Science. 517 : 52-60 Retrieved from https://doi.org/10.1016/j.jcis.2018.01.092 